\section{A ESCULTURA FAMILIAR: APLICAÇÕES TERAPÊUTICAS NAS TERAPIAS SISTÊMICAS}

\author{
THE FAMILY SCULPTURE: THERAPEUTIC APPLICATIONS IN SYSTEMIC THERAPIES
}

\author{
LA ESCULTURA FAMILIAR: \\ APLICACIONES TERAPÉUTICAS EN TERAPIAS SISTÉMICAS
}

\begin{abstract}
RESUMO: A técnica da Escultura Familiar é uma forma de representar as relações entre elementos através da sua colocação no espaço. É um processo não verbal, dinâmico, simbólico e ativo. A escultura familiar tem como objetivo expressar perceções, sentimentos, emoções e narrativas por meio de imagens e introduzir mudanças nas histórias e nas interações familiares. Realiza-se nas fases de avaliação e no curso da terapia. A família do passado, do presente, do futuro, a família ideal/desejada e outras como a escultura do segredo/assunto não revelado, dos medos, dos desejos, dos sonhos, dos lutos e das forças, são alguns exemplos de possíveis esculturas com e sobre a família. A escultura desenvolve-se em 5 estádios: instrução, realização da escultura, esculturas com movimento, feedback e reenquadramento/ comentário. Enquadrada segundo uma epistemologia pós-moderna, a escultura evidencia narrativas dominantes, faz emergir narrativas subdominantes e permite a mudança histórica e das relações e interações familiares através da experiência e não dos discursos.
\end{abstract}

Palavras-chave: Escultura da família; Terapia familiar; Narrativa; Emoção; Mudança.

ABSTRACT: The Family Sculpture is a technique for representing the relationships between elements by their placement in the space. It's a non-verbal, dynamic, symbolic and active process. The family sculpture expresses perceptions, feelings, emotions and narratives through images and introduces changes in family histories and interactions. The sculpture can be developed in the evaluation and during therapy. The family of the past, the present, the future, the ideal/desired family and others, such as, the sculpture of the secret/ unrevealed subject, fears, desires, dreams, mourning and forces, are just some of the possible sculptures of and with the family The sculpture is developed in 5 stages: instruction, realization of the sculpture, sculptures with movement, feedback and reframing/comment. Framed according to a postmodern epistemology the sculpture highlights dominant narratives, allows the emergence of subdominant narratives and introduces changes in histories, relationships and interactions in the family, through experience and not by discourses.

Keywords: Family sculpture; Family therapy; Narrative; Emotion; Change.

RESUMEN: La técnica de la Escultura de la Familia es una forma de representar las relaciones entre los elementos a través de su ubicación en el espacio. Es un proceso no verbal, dinámico, simbólico y activo. La escultura familiar tiene como objetivo expresar percepciones, sentimientos, emociones y narrativas a través de imágenes e introducir cambios en las historias e interacciones familiares. Se lleva a cabo en las fases de evaluación y en el curso de la terapia. La familia del pasado, el presente, el futuro, la familia ideal/deseada y otras como la escultura del secreto, de los miedos, deseos, sueños, duelo e fuerzas son algunos ejemplos de esculturas de la e con la familia. La escultura se desarrolla en 5 etapas: instrucción, realización de esculturas, esculturas con movimiento, feedback y reencuadre/ comentario. Enmarcada según una epistemología posmoderna, la escultura evidencia narrativas dominantes, hace emerger narrativas subdominantes y permite el cambio histórico y las relaciones e interacciones familiares a través de la experiencia y no del discurso.

Palabras clave: Escultura familiar; Terapia familiar; Narrativa; Emoción; Cambio.
JOANA SEQUEIRA

Instituto Superior Miguel Torga, Coimbra, Portugal. Sociedade Portuguesa de Terapia Familiar, Lisboa, Portugal.

Recebido em 27/01/2020 Aprovado em 05/11/2020 


\section{INTRODUÇÃO}

Esculpir a família é representar as relações entre os diferentes elementos através da colocação dos seus corpos no espaço. É um processo dinâmico, simbólico, ativo e não linear. Retrata, não verbalmente, as relações no espaço e no tempo onde os acontecimentos são percebidos e vividos (Duhl, Duhl, \& Kantor, 1973). Corresponde a um arranjo de pessoas e/ou objetos que exprime analogicamente as suas relações, num momento particular. Baseia-se em três dimensões do funcionamento da família: a comunicação não verbal, a interação no "aqui e agora" e a experiência agida/ vivida de pensamentos, sentimentos e comportamentos. A escultura faz emergir a ação, a linguagem figurativa, metafórica e corporal. São exploradas as dimensões visuais, simbólicas, físicas e sensorais sobre o assunto ou processo em foco (Papp, Scheinkman, \& Malpas, 2013). As pessoas exprimem as relações, os elementos envolvidos, os problemas e sentimentos e estas imagens constituem formas alternativas de comunicar as suas narrativas e visões sobre algo. A escultura da família revela percepções pessoais sobre comportamentos, sentimentos, emoções e narrativas, em vários contextos ao longo e no tempo (Robert \& Simon, 1998). Clarifica perspetivas, comportamentos e sentimentos dos elementos sobre e na família.

A escultura, enquanto técnica, emerge na terapia familiar experiencial simbólica, no início do desenvolvimento da terapia familiar entre os anos 60 e 70 . Implica a expressão dos sentimentos e a sua experiência partilhada como via para a realização pessoal e familiar. Carl Whitaker, Virgínia Satir e Peggy Papp são alguns dos nomes ligados à terapia experiencial simbólica. Whitaker defendia uma abordagem espontânea e intuitiva destinada a persuadir e criar condições para que os diferentes elementos da família fossem eles mesmos. Virginia Satir, elemento do grupo inicial do MRI (Mental Research Institute), em Palo Alto, enfatizava a comunicação e a experiência emocional como pressupostos do funcionamento familiar saudável a serem promovidos na terapia (Satir, 1972).

Os autores Fred e Bunny Duhl, do Boston Family Institute, introduziram várias técnicas expressivas, em particular a escultura, na terapia familiar experiencial (Duhl, Duhl, \& Kantor, 1973). A terapia experiencial implica um processo ativo de aprendizagem e crescimento, para todos os envolvidos, e desenvolve a capacidade de cada pessoa (re)aprender comportamentos e interações, através da vivência de novas experiências que sejam significativas e libertadoras. A experimentação de novos comportamentos, mais do que a compreensão do comportamento, é o potenciador da transformação e da mudança (Cardoso, 1996).

No modelo experiencial assumiram-se duas posturas diferenciadas quanto ao papel das técnicas ativas, entre elas a escultura. Walter Kempler e Carl Whitaker não usavam técnicas específicas (Whitaker \& Bumberry, 1988). Consideravam que a personalidade do terapeuta, o seu self, constituía o elemento transformador, não as técnicas específicas ou sofisticadas que utilizavam. O importante não é tanto o que o terapeuta faz, mas o que o terapeuta é! O terapeuta ajuda a família sendo apenas ele mesmo. Whitaker representava esta ideia. Era criativo, espontâneo, estimulava a autenticidade e abertura dos pacientes.

Uma outra vertente da terapia familiar experiencial valorizava as técnicas estruturadas, como a escultura e a coreografia da família (Papp, 1982a,1982b, 1983) para criar intensidade emocional na terapia, fazer emergir as dificuldades, problemas e relações, por meio da comunicação não verbal. Papp, Silverstein e Carter (1973) aplicaram a escultura familiar numa perspetiva transgeracional, identificando temas-chave nas famílias nuclear e extensa, procurando promover um realinhamento e mudança de padrões de interação. Virginia Satir (1972) trabalhava 
com a família de forma a despertar as emoções não comunicadas explicitamente utilizando, para este efeito, múltiplas técnicas ativas, entre elas, a dramatização, o jogo de papéis e a escultura.

Outros terapeutas familiares, não associados à abordagem experiencial, como Minuchin (1974) e Madanes (1980), desenvolviam dramatizações dos problemas e de dinâmicas familiares perturbadas na sessão. Era pedido que os pacientes dramatizassem de forma ativa e teatral o que acontecia e o que sentiam e, posteriormente, os comportamentos ou interações alternativas e mais ajustadas, também vivenciadas de formas ativas e teatralizadas. Independentemente das posições teóricas, todos os terapeutas referidos utilizaram técnicas/abordagens simbólicas, evocativas e que enfatizam a linguagem não verbal e, especificamente, a escultura da família.

Desde os anos 70 até a atualidade, a escultura da família foi integrada por diversos modelos terapêuticos e atualmente também pelas abordagens contemporâneas. É aplicada de distintas formas, com múltiplas variações, ajustando-se ao contexto e fim com que é desenvolvida (Papp, Scheinkman, \& Malpas, 2013). A aplicação da escultura no quadro da terapia focada nas soluções (TFS) (Reiter, 2016), na terapia baseada na teoria dos sistemas familiares internos (Deacon \& Davis, 2001) e no Ackermam Institute, na terapia de casal focada nas emoções (Papp, Scheinkman \& Malpas, 2013) são exemplos da integração da escultura nas abordagens pósmodernas. Na terapia focada nas soluções são introduzidas a escultura da família desejada (como os pacientes gostariam que a sua família fosse), a escultura da família após o milagre (como a família será depois do milagre ter ocorrido) e a escultura das exceções (como é/foi a família quando o problema não está/estava presente). A escultura baseada neste modelo pretende sublinhar, amplificar e ancorar (pela experiência) as imagens das exceções e das soluções desejadas.

As esculturas focadas nas soluções são metáforas que expressam experiências e colaboram no desenvolvimento do processo de construção de mudanças e soluções (Clarke, 2014; Reiter, 2016). Papp, Scheinkman e Malpas (2013), do Ackerman Institute, utilizam a escultura para evidenciar os impasses da terapia e os ciclos relacionais disfuncionais que ocorrem entre os elementos. Através das esculturas promovem formas diferentes de olhar para a situação, abordam assuntos difíceis e sensíveis e expõem nuances experienciais que se encontram à margem da compreensão das pessoas.

Também na formação e treino de profissionais que trabalham com famílias (e.g. terapeutas familiares, enfermeiros etc.) a escultura tem sido aplicada de forma a evidenciar dinâmicas familiares emocionais e estruturais complexas. Esculpindo transformando dinâmicas por meio da vivência de experiências alternativas - e reesculpindo com foco no desenvolvimento pessoal do terapeuta (Andersen, Larsen, 2015; Costa, 1992; Keltner \& Gillett, 1984).

Embora a escultura seja uma técnica com origem nas terapias familiares de $1^{\text {a }}$ ordem, a sua utilização transcende estes modelos e é também observável nas terapias de $2^{\text {a }}$ ordem, refletindo a tendência atual de integração de modelos nas terapias familiares (Brewster \& Scheinberg, 2012; Fraenkel, 2009; Fraenkel \& Pinsof, 2001; Lebow, 2003). Nestas abordagens, em particular nas terapias narrativas, centrada na solução e nas emoções, a escultura permite evidenciar a experiência subjetiva de cada um (emoções, crenças e histórias), bem como o bloqueio e perturbação das narrativas e padrões de funcionamento da família (promoção da oscilação temporal e desbloqueio do tempo estático e passado). Permite também experimentar formas de interagir diferentes, transformar papéis rígidos, desfazer rótulos, propor metáforas que evidenciam e potenciam processos
1 Brewster, M. \& Scheinberg, M. (2012). The Ackerman Institute relational approach. Unpublished manuscript. 
relacionais e narrativos novos e valorizar linguagem não verbal. É ainda uma via para a conexão, comunicação e evolução da família e dos seus elementos.

Apresenta-se uma proposta da escultura familiar a partir da experiência clínica sobre a sua aplicação e da reflexão desenvolvidas, tendo como base a versão original de Duhl, Duhl e Kantor (1973) e incluindo os contributos das terapias pós-modernas, em particular a terapia narrativa. São descritos os objetivos, formatos e aplicações da escultura da família e sugerem-se versões e aplicações contemporâneas.

\section{MÉTODO E PROTOCOLO DA ESCULTURA DA FAMÍLIA}

Existem três formas de escultura que podem ser categorizadas em função das pessoas envolvidas: escultura individual, escultura diádica/de casal e a escultura familiar/ou de grupo. Todas seguem os mesmos aspetos gerais. Este trabalho centrase escultura familiar.

\section{Objetivos}

A escultura familiar pode realizar-se na etapa da avaliação/diagnóstico no curso do processo terapêutico.Os objetivos são: (a) Clarificar, explicitar e focar áreas da interação e funcionamento familiar; (b) Amplificar, não verbalmente, aspetos específicos da dinâmica da família, relevantes na avaliação e no processo terapêutico; (c) Parar processos de excessiva verbalização, que anulam o espaço para que os elementos da família possam ser espontâneos e sinceros; (d) Evidenciar narrativas dominantes e subdominantes e suas emoções; (e) Abordar metaforicamente assuntos difíceis ou tabu, que se considera relevante/desbloqueador serem expressos e colocados no processo terapêutico; (f) Focar nos processos relacionais e sair de conteúdos específicos que podem dominar o discurso e narrativas dos sujeitos; (g) Potenciar perturbações intensas na estrutura familiar; (h) Aumentar e amplificar as emoções da sessão e (i) Promover o toque e o contacto físico entre as pessoas escultor e esculpidos.

\section{Condições de realização}

Para a realização da escultura, a relação terapêutica deve ser percebida como segura. Neste sentido, a realização da escultura em fases iniciais da terapia só deve ser desenvolvida quando a relação terapêutica está estabelecida. As pessoas apenas se envolvem quando sentem que é seguro e útil para a terapia, para si e para a família. Os terapeutas avaliam o grau de segurança da relação, devem conhecer bem a técnica, a forma de desenvolvimento, suas indicações e objetivos.

Dependendo do contexto da realização da escultura podem envolver-se todas as pessoas da família presentes, apenas algumas, os terapeutas e os observadores (quando estes estão presentes na sessão).

Idealmente devem estar no mínimo duas pessoas da família envolvidas. As famílias mais numerosas usualmente aderem com facilidade às esculturas, pois encaram a atividade de forma lúdica e menos expositiva e confrontativa, uma vez que vão emergir muitas esculturas que evidenciam várias narrativas sobre o tema em causa. Também é possível realizar uma escultura da família com um só paciente. Nestes casos, os elementos da família podem ser nomeados pelos terapeutas, os observadores ou "material" disponível na sala e cabe ao escultor esta escolha. 
A escultura deve realizar-se numa sala cuja mobília seja facilmente movível e possa ser utilizada na expressão dramática de forma simbólica. Decorre durante a sessão, preferencialmente na fase inicial ou intermédia, antes do intervalo, garantindo-se assim a existência de tempo disponível para a realização do trabalho.

O terapeuta pode introduzir a escultura no decorrer de uma sessão para explorar, evidenciar e experimentar algo que surge nesse contexto ou pode introduzi-la no início da sessão com objetivos e estratégias previamente definidos, para trabalhar em áreas específicas do processo terapêutico. $\mathrm{O}$ terapeuta deve apresentar o trabalho a desenvolver num momento em que todos estejam envolvidos e sem outros assuntos pendentes ou no decorrer da sessão, dar as informações e esclarecimentos necessários à realização, de forma breve, clara e objetiva.

\section{Variantes da escultura}

Existem múltiplas variantes da escultura familiar e estas são escolhidas pelo terapeuta, em função dos objetivos propostos e do contexto. A imaginação e a criatividade do terapeuta e da família permitirão um leque de escolhas e formas que não estão pré-definidas. As esculturas "clássicas" desenvolvidas pelos modelos experiencial e estratégico são a família do passado, do presente, do futuro e a família ideal/desejada (Duhl, Duhl, \& Kantor, 1973; Satir, 1972). Porém, outras esculturas podem ser propostas, como, por exemplo, a escultura do segredo ou assunto não revelado, dos medos, dos desejos, dos sonhos, dos lutos, das forças, das vulnerabilidades, dos valores, de acontecimentos específicos no futuro, passado ou presente (e.g. comemorações, rituais, férias), de uma memória relevante e de uma narrativa específica, de algo que cada pessoa queira muito expressar ou de uma questão importante para cada um.

O tempo da escultura pode ser vago, propositadamente, mas também pode ser especificado - dependendo dos objetivos. Por exemplo, se é relevante expor uma dimensão específica que se associa a um acontecimento num tempo previsível, como a entrada na universidade de um filho, pode ser pedida uma escultura que evidencie exatamente esse tempo, de forma mais clara ou ambígua (escultura num tempo que coincida com a entrada na universidade, sem explicitar a entrada na universidade, ou pedir objetivamente que façam a escultura da família quando o filho tiver entrado para a universidade em $\mathrm{x}$ meses/anos).

As esculturas podem incluir apenas as pessoas da família presentes na sessão, mas também outras pessoas, que os escultores queiram incluir, e estas pessoas podem ser representadas pelos terapeutas e equipe de observadores, caso existam.

\section{Papéis}

Os papéis envolvidos na escultura familiar incluem o escultor (que esculpe e revela a sua visão, narrativas e sentimentos, relativamente à questão a representar), o terapeuta (que guia o escultor, clarifica os procedimentos, suporta e auxilia os participantes na escultura, os esculpidos (as pessoas que fazem parte da escultura) e a audiência (as pessoas que observam a escultura).

É o terapeuta que guia e orienta o processo, devendo assumir as regras da realização da escultura, para que os pacientes assumam um comportamento isomórfico ao seu. Ou seja, deve falar apenas o indispensável na instrução e para garantir que o processo seja bem desenvolvido, focar na dimensão não verbal, exemplificando fazendo e não descrevendo. Deve apresentar todo o procedimento 
em pé e agir como se fosse o escultor. Os passos devem ser realizados pausadamente, apenas são verbalmente ditas as instruções estritamente necessárias. O processo deve ser exemplificado com o coterapeuta ou com elementos da família, pedindo a permissão para os esculpir, garantindo que não há constrangimento ou incômodo por serem envolvidos ativamente, por meio do toque e da movimentação no espaço. Tomam especial atenção ao tempo, que deve ser pausado, ajudam a que as ações e instruções do escultor sejam seguidas pelos elementos envolvidos e garantem que a imagem esculpida corresponda àquela que o escultor pretende. O terapeuta pode colocar-se no lugar do escultor, na sua escultura final, para que este "se possa ver" na imagem que esculpiu e se esta corresponde ao que pretende, para, posteriormente, finalizar a escultura e assumir o seu papel no conjunto com os restantes elementos.

O papel do terapeuta é fundamental para que a tarefa seja vivida de forma confortável e sem qualquer juízo de valor ou avaliação. Quanto mais confortável e seguro o terapeuta estiver na apresentação e desenvolvimento da atividade, mais facilmente os pacientes sentem o mesmo. Após a diminuição da ansiedade inicial e a exemplificação e instrução do terapeuta, na maioria dos casos, todos desenvolvem as suas esculturas, participam e revelam as emoções e as narrativas que pretendem.

O escultor é quem realiza a escultura. Pode existir apenas um escultor ou vários. A escolha do escultor depende dos objetivos. O mais frequente é que todos os elementos da família em terapia sejam escultores. Todos esculpem a sua escultura e todos são esculpidos nas esculturas dos outros. Todos os elementos da família que participam na terapia podem realizar as esculturas. Apenas crianças muito pequenas ou pessoas muito idosas poderão ter limitações na realização da escultura. Nestes casos, o terapeuta deverá equacionar a pertinência e utilidade da técnica na sessão, tendo em conta que os elementos da família não estão em condições semelhantes na sua realização, podendo os objetivos e ganhos ficarem condicionados.

O escultor integra na sua imagem a narrativa do que está a ser solicitado, as emoções, suas e dos outros, a perceção das interações, das relações e do papel de cada pessoa na situação em causa. Coloca as pessoas relativamente umas às outras, a si e, caso deseje, pode também incluir o terapeuta, no contexto e cenário que estrutura como desejar, com os objetos e espaço que tem à sua disposição e que poderão ser moldados real e simbolicamente a seu gosto.

Os esculpidos (podem também designar-se como barro, argila etc., são o material da escultura) são os restantes elementos da família ou outras pessoas que o escultor envolva no processo. Estes são colocados pelo escultor, tocandolhes e movimentando-os para onde e como deseja que eles estejam. Os elementos esculpidos devem deixar-se esculpir, obedecer e ser colocados da forma e no contexto que o escultor pretende. Enquanto material sem vida própria, não se mexem e não falam. A forma como ficam na escultura deve ser totalmente moldada e executada pelo escultor. O terapeuta deve garantir que o processo decorra exatamente desta forma e sem qualquer verbalização.

A audiência são as pessoas que não são ativamente envolvidas na escultura (observadores, terapeutas ou elementos da família) que, por observarem, podem, na fase do comentário, pontuar o processo, de acordo com instruções específicas que devem ser referidas pelo terapeuta. 
Estádio 1. Instrução: $O$ terapeuta levanta-se, afasta as cadeiras onde estavam sentados para criar um espaço amplo no centro da sala. Também solicita aos elementos da família que se coloquem de pé. O terapeuta dá instrução depois de ter apresentado brevemente o objetivo do trabalho, dizendo, por exemplo, "temos comunicado em muitos momentos através das palavras, hoje vamos comunicar sem palavras e para isso vamos fazer esculturas". Continua apresentando a instrução "imaginem que todos são barro e que cada um de vós é o escultor desse barro. Pretende esculpir a imagem que tem sobre a vossa família no momento atual. Deverá colocar todas as pessoas de acordo com a sua imagem, moldando-as como quer que elas estejam, ou seja, tocando-lhes e colocando-as nas posições e com as expressões pretendidas. É o escultor que molda o barro, de acordo com a sua imagem. O barro não tem vida própria, não me mexe e não fala, tem de ser o escultor a colocá-lo como pretende, moldando-a com as suas mãos. O espaço onde estamos pode ser utilizado como desejarem". Para ajudar a definição da imagem a esculpir pode acrescentarse o seguinte: "respire fundo e pense numa imagem, se for melhor, feche os olhos, imagine uma foto que enviaria a alguém que estivesse do outro lado do mundo e, sem palavras explicativas, a pessoa, ao receber essa imagem, perceberia o que estava esculpido. Pode ser uma imagem concreta, real ou simbólica, a imagem é sua!".

Em seguida, o terapeuta exemplifica fazendo ele mesmo, colocando as pessoas com as expressões e nas posições e locais que pretende. Deve exemplificar o processo, totalmente em silêncio, e não deve introduzir conteúdos, ou seja, mostra como se faz, mas nunca exemplifica a escultura que vai pedir à família. Caso as pessoas mostrem dificuldade em definir uma imagem, o terapeuta poderá dar instruções que ajudem à concretização da imagem e atmosfera do espaço pedindo, por exemplo, "pense quem está, como estão, a fazer o quê, como é o espaço e a forma como se sente nele, a mensagem geral que pretende evidenciar" e, de forma progressiva, vai ajudando o escultor a definir a sua imagem.

Se for para todos esculpirem a sua escultura, o terapeuta deve garantir que cada um tem a sua imagem a esculpir definida antes de se iniciar o processo. Por isso, deve ouvir a imagem de cada um "em segredo", de forma a garantir que não façam as suas esculturas a partir do que foram observando antes de si e evita que as esculturas dos vários elementos sejam influenciadas pelas imagens que vão sendo realizadas.

Pode ser o terapeuta a definir quem começa as esculturas ou alguém toma a iniciativa de começar. A ordem da realização das esculturas pelos vários escultores deve ir alternando e realiza-se uma escultura de cada vez. Se forem realizadas duas esculturas, a instrução para a primeira é dada, todos executam e apenas em seguida o terapeuta introduz a outra escultura e clarifica novamente a instrução. Desta segunda vez dizendo que o processo é o mesmo, mas a escultura a fazer será outra.

Estádio 2. Realização da escultura: O escultor, depois de ter definido a sua imagem, começa a definir a situação a representar (situações, eventos, significados, ou processos familiares). Todos assumem que as personagens são de barro cabendo, portanto, ao escultor moldá-las, tocando-lhes e moldando-lhes a expressão e a postura. Quando não é possível (por exemplo porque "não conseguem tocar") dão instruções mínimas. Depois de colocar os outros na posição desejada, o escultor deve colocar-se a si, caso esteja incluído na cena. O terapeuta continua a encorajar a modelação corporal e, se necessário exemplifica, sem recorrer ao discurso. Mantêm-se todos de pé e em total silêncio, durante o tempo em que todos os escultores realizam as esculturas.

Nova Perspectiva Sistêmica, v. 29, n. 68, p. 19-30, dezembro 2020. 
O escultor deverá escolher quem vai participar dessa escultura podendo, no processo, englobar pessoas que não estão presentes e que podem ser representadas por elementos da equipe ou por objetos. A estas personagens também devem ser atribuídas características e sentimentos que se revelem na sua postura e colocação no espaço. Quando a escultura está finalizada o terapeuta pergunta ao escultor se está finalizada, se quer mudar ou acrescentar algo. Em seguida tenta que todos memorizem a imagem criada na escultura, pedindo para que permaneçam na posição durante uns segundos. Tira uma foto da escultura realizada, caso a família concorde, de preferência com a câmara do celular de alguém da família ou com o seu, caso a família não coloque nenhum problema.

Todo o processo se desenrola em silêncio, em pé e para todos os escultores, um de cada vez. O terapeuta, após a finalização de cada escultura, dá um breve tempo para as pessoas poderem descontrair e sair das posições em que estavam (pode exemplificar e relaxar o corpo movimentando-se de forma a descontrair da tensão), retomando depois a posição, de pé, em círculo, em torno do espaço amplo criado na sala para a encenação e começam uma nova escultura. Deve ser o escultor a realizar todo o cenário; o terapeuta apenas ajuda, se este pedir ou se perceber que o escultor está a ter dificuldades em realizar a imagem, mas, ainda assim, age sempre em função das instruções do escultor e não introduz qualquer conteúdo ou processo seu. Quando todos tiverem realizado as suas esculturas o terapeuta pode finalizar nesta etapa e fazer um intervalo, sem qualquer comentário.

Estádio 3. Esculturas com movimento: Esta etapa é opcional e pode não acontecer. Depois do escultor ter colocado todos os elementos da família no espaço e de estarem claramente definidas as suas posições, o terapeuta pode encorajar a família a movimentar-se, a agir sem palavras, dando origem a esculturas vivas. Nesta fase, a participação dos restantes elementos pode ser mais ativa, podendose, inclusivamente, esculpir, sempre não verbalmente, sentimentos e percepções alternativas que podem traduzir-se em diferentes esculturas. Qualquer elemento da família pode esculpir a partir da escultura de base, devendo colocar as pessoas no espaço e colocando-se também a si mesmo. As visões alternativas que resultam desta interação proporcionam à família a possibilidade de viver configurações relacionais alternativas, propostas por si ou pelos outros. As instruções para a realização da escultura são as mesmas.

Estádio 4. Feedback: Este é o momento em que os elementos da família partilham os seus sentimentos relativamente às esculturas. Referem apenas o que sentiram nos seus papéis/posições nas esculturas. Partilham a escultura em que se sentiram menos bem e que aquela em que se sentiram melhor, entre todas as esculturas de todos os elementos. Não deve ser dado muito espaço de verbalização, apenas se foca o que sentiram dizendo - "escolha algumas palavras que expressem o que sentiu, apenas o que sentiu, não o que pensou ou a sua interpretação da escultura". O que sentiram como escultor e esculpidos também deve ser explicitado, sem racionalização e explicação. Esta partilha é empaticamente suportada pelo terapeuta, que facilita a comunicação familiar em torno da situação dramatizada na escultura, sem explicações, perguntas ou justificações do que aconteceu.

Frequentemente, as famílias vivenciam elevada tensão e reações emocionais fortes, como nervosismo e choro. É normal que aconteça e o terapeuta deve valorizar a capacidade de exposição e suportar o disclousure, focado nos processos e não nos conteúdos. O terapeuta pode reforçar o envolvimento das pessoas e agradecer a confiança que mostraram ao realizar a tarefa da forma como fizeram. 
A escultura não deve ser alvo de discussões e reflexões pois corre-se o risco de que o seu impacto se possa perder nas considerações verbais da família ou do terapeuta. Em conclusão: deve dar-se espaço à partilha de sentimentos, mas não à discussão do processo e conteúdos.

Também a audiência, os observadores, podem partilhar "palavras-chave" relativamente ao processo emocional, centrando-se especialmente nos comportamentos não verbais dos intervenientes.

Estádio 5. Reenquadramento/comentário: $O$ terapeuta partilha com a família o seu reenquadramento, devolvendo-lhes uma imagem compreensiva e interacional da experiência vivida, enquadrada nas narrativas da terapia e da família. Os aspetos interacionais e relacionais da escultura familiar são considerados, quer na perspetiva da família, e, se necessário, na dimensão individual de cada elemento, enquanto pessoa diferenciada. Deve referir-se ao processo em si e às emoções que este deixa transparecer relativamente às relações na família. Pode nomear o que a escultura evoca em si e nos colegas observadores, enquanto processos da família, impacto e potencial transformador. Este reenquadramento deve ser muito breve e cirúrgico, dizendo, por exemplo, "foi muito importante perceber como vocês todos mostraram o que é difícil conversar na vossa família!" ou "hoje os medos deixaram de estar dentro de cada um de vós e passaram a ser visíveis/expressos e juntos poderão decidir o que fazer com eles".

O terapeuta também pode optar por substituir o comentário, fazendo uma escultura do que pretende que a família receba e leve de parte da equipe terapêutica. Uma escultura que evoque a imagem global do(s) processo(s) ocorrido(s), de uma forma sistémica, enfatizando a transformação ocorrida e o potencial que resulta do processo. Se optar por fazer "a sua escultura”, em jeito de comentário, deve seguir as regras já referidas. Pode apenas partilhar também em "palavras-chave” o que sentiu no processo! A sessão deve terminar neste momento, sem qualquer outra interação ou tema.

\section{Dificuldades na realização da escultura}

$\mathrm{Na}$ escultura familiar podem ocorrer dificuldades no desenvolvimento do processo e na concretização, limitando os ganhos terapêuticos previstos. Estas dificuldades podem associar-se ao terapeuta e aos elementos da família. Relativas ao terapeuta estão as questões associadas à falta de domínio e conhecimento da técnica dos seus pressupostos, objetivos e condução. São mais frequentes as dificuldades no momento da instrução quando o terapeuta não dá a instrução de forma clara ou completa, o que desvirtua a realização. Também ocorrem dificuldades por condução inadequada do processo, por exemplo, deixar que as pessoas falem na escultura ou deem instruções aos outros elementos sobre como se colocar.

Outras dificuldades são relativas aos elementos da família. Algumas pessoas e algumas famílias têm dificuldades em sair do seu registo comunicacional habitual e endereçam explicitamente a ambivalência face à mudança ao não abdicar deste registo. Aproximam-se do conceito de resistência, não tanto para a mudança, mas para a experimentação de uma nova situação interacional. 
Outra dificuldade comum é a representação indiferenciada da família de forma estática ou do ideal de família, onde os elementos não esculpem qualquer outra situação que não esta, apesar das instruções. É solicitada, por exemplo, a família do passado, do presente ou do futuro, mas o resultado é sempre, com pequenas diferenças, uma imagem familiar fixa. Este processo pode ter uma função protetora, face a qualquer possível ameaça que as esculturas pedidas possam desencadear. A escultura, neste caso, evidencia a não mudança e a dificuldade ou receio dos elementos em assumirem posições diferenciadas ou mesmo contrárias e de veicular uma narrativa distinta daquela que domina o quadro familiar.

Nalgumas situações o escultor não segue as instruções e representa, independentemente do pedido, a satisfação de um desejo ativo/presente relativamente à situação familiar. Podemos então depararmo-nos com uma situação em que não é a visão familiar daquele indivíduo que está em causa, mas sim a comunicação de algo específico através da escultura.

Noutras situações o escultor pode evidenciar na escultura os seus sentimentos de zanga, raiva ou decepção. Novamente, estamos perante uma situação em que o objetivo inicial da escultura não é alcançado e é relevante retirar algumas informações que, noutros contextos, eventualmente, não seriam abordadas.

Por último, situações em que o escultor utiliza a escultura familiar para um fim pessoal ou familiar particular, não atendendo ao objetivo apresentado para a escultura.

Embora estas dificuldades possam ser potencialmente disfuncionais e refletir as dinâmicas da família, a conotação positiva destes processos poderá promover perturbação na narrativa atual, potenciando alguma mudança. Apesar da dificuldade de realização da atividade, o terapeuta pode conotar positivamente as questões que se tornaram evidentes e que a família comunica. Devolve um comentário com reenquadramento ou faz uma escultura que sirva esta finalidade. A capacidade dos terapeutas retirarem ganhos terapêuticos destas situações depende da sua flexibilidade e da introdução de informação nova e não previsível que pode gerar diferença.

\section{CONCLUSÕES}

A escultura familiar é hoje uma técnica utilizada em inúmeros contextos e por diversos terapeutas de distintos modelos teóricos, como sugerem as abordagens integrativas atuais das terapias familiares sistémicas. A sua pertinência extrapola o modelo experiencial, constituindo-se como uma técnica importante nas terapias quer de $1^{\text {a }}$ quer de $2^{\text {a }}$ ordem. As suas utilidades e vantagens terapêuticas, no domínio experiencial, permitem trabalhar questões complexas onde a verbalização não é produtiva.

Embora associada a um modelo de $1^{\circ}$ cibernética, a escultura teve como primeira ênfase o foco na dimensão pragmática da dinâmica familiar e na experiência de comportamentos e relações. Enquadrada segundo uma epistemologia pós-moderna, permite evidenciar questões muito além dos comportamentos e estilos de interação. Permite evidenciar narrativas dominantes, fazer emergir narrativas alternativas subdominantes que, por esta via, têm possibilidade de ser comunicadas, sem estarem expostas à força ocultadora das histórias com mais poder ou mais veiculadas. Valoriza-se, pela via não verbal, a multiplicidade narrativa através da facilitação e emergência de múltiplas versões - esculturas - dando voz e espaço a que cada um dos elementos, individualmente, possa partilhar a sua versão e a sua história. Cada escultura evoca múltiplas histórias e como as esculturas não são explicadas 
nem descritas na sessão, apenas sentidas e vividas, não se objetiva nem limita a visão que delas emerge, não resulta uma visão, uma narrativa, mas, antes, multiplicamse as leituras e sentidos, uma vez que cada pessoa fará múltiplas interpretações. Assim, se facilita o desbloqueio de histórias que organizam as narrativas bloqueadas e restritivas que constrangem as interações entre as pessoas. Assuntos que não são falados, porque são segredos, porque transportam sofrimento, conflitos ou bloqueios relacionais podem ser expressos na linguagem não verbal, passando, assim, a serem integrados, sentidos e modificados individualmente e em família.

A escultura respeita a dimensão ética da família e de cada elemento e, também, a dimensão estética, pois permite evidenciar narrativas individuais e permite encontrar e construir um "padrão que liga" as diferentes versões (Bateson, 1972).

A forma como uma escultura decorre e o seu impacto na terapia relacionam-se com muitos fatores, entre eles, a qualidade da relação terapêutica com a família, a fase da terapia, os objetivos, a adesão da família ao processo, o domínio que o terapeuta tem da técnica e a sua criatividade.

A escultura evidencia visões e emoções através da linguagem não verbal, assistese a uma diminuição das defesas de cada pessoa no processo. As ações falam mais e melhor do que as palavras. As vantagens desta técnica são inúmeras: expressar sentimentos reprimidos, reavivar a comunicação analógica e o brincar e simbólico na família, envolver pessoas menos ativas na sessão, aumentar a intensidade emocional, expressão pela ação de dimensões difíceis de comunicar como, por exemplo, a solidão, medo, hostilidade, raiva, amor etc., refletir e desbloquear impasses na terapia, conectar o terapeuta e a família colocando o primeiro numa posição de colaboração e ativador de processos (e não como perito), promover e valorizar a espontaneidade da família e dos seus elementos, disponibilizar posições pessoais relativamente a diversas questões, evidenciar padrões de funcionamento repetitivos, vivência de configurações alternativas e visões múltiplas e expressar a qualidade e forma das relações estabelecidas.

Justifica-se o aprofundamento e desenvolvimento das aplicações clínicas da escultura da família, a continuação da sua fundamentação conceptual, tendo em conta as múltiplas variantes e aplicações e a investigação sobre sua eficácia e utilidade terapêutica.

\section{REFERÊNCIAS}

Andersen, H. \& Larsen, K. (2015). Sculpting with people - An experiential learning technique. Nurse Education in Practice, 15, 556-560. http://dx.doi.org/10.1016/j. nepr.2015.07.04

Bateson, G. (1972). Steps to an ecology of mind. Chicago, US: University of Chicago Press.

Cardoso, M. (1996). A Utilização da Escultura na Terapia de Casal. Cadernos de Consulta Psicológica, 12, 33-38.

Clarke, J. (2014). Utilization of clients' metaphors to punctuate solution-focused brief therapy interventions: A case illustration. Contemporary Family Therapy, 36(3), 426-441. https://doi.org/10.1007/s10591-013-9286-y

Costa, L. (1992). Family sculpting in the training of marriage and family counselors. In R. L. Smith \& P. Stevens-Smith (Eds.) Family counseling and therapy: Major issues and topics (pp. 261-272). Ann Arbor: MI: ERIC Counseling and Personnel Services Clearinghouse. 
Deacon, S. \& Davis, J. (2001). Internal Family Systems Theory: A Technical Integration. Journal of Systemic Therapies, 20(1), 45-58. https://doi.org/10.1521/ jsyt.20.1.45.19410

Duhl, F., Duhl, B., \& Kantor, D. (1973). Learning, space and action in family therapy: A primer of sculpture. In D. Block (Ed.), Techniques of family psychotherapy (pp. 119-139). New York: Grune \& Stratton.

Fraenkel, P. (2009). The Therapeutic Palette: A Guide to Choice Points in Integrative Couple Therapy. Clinical Social Work Journal, 37(3), 234-247. https://doi. org/10.1007/s10615-009-0207-3

Fraenkel, P. \& Pinsof, W. (2001). Teaching Family Therapy-Centered Integration: Assimilation and Beyond. Journal of Psychotherapy Integration, 11, 59-85. https://doi.org/10.1023/A:1026629024866

Keltner', B. \& Gillett, P. (1984). Family Sculpture. Journal of Nursing Education, 28(8), 361-363.

Lebow, J. L. (2003). Integrative approaches to couple and family therapy. In T. L. Sexton, G. R. Weeks, \& M. S. Robbins (Eds.), Handbook of family therapy: The science and practice of working with families and couples (pp. 201-225). London: Brunner-Routledge.

Madanes, C. (1980). Protection, paradox and pretending. Family Process, 19(1), 73-85. https://doi.org/10.1111/j.1545-5300.1980.00073.x

Minuchin, S. (1974). Families and family therapy. New York: Harvard University Press.

Papp, P. (1982a). Staging reciprocal metaphors in couples therapy. Family Process, 21(4), 453-467. https://doi.org/10.1111/j.1545-5300.1982.00453

Papp, P. (1982b). The use of fantasy in a couple's group. In M. Andolfi \& I. Zwerling (Eds.), Dimensions of family therapy (pp. 73-90). New York: The Guilford Press.

Papp, P. (1983). The process of change. New York: The Guilford Press.

Papp, Pry Silverstein, 0., \& Carter, E. (1973). Family sculpting in preventive work with "well families". Family Process, 12(2), 197-212. https://doi. org/10.1111/j.1545-5300.1973.00197.x

Papp, Pr, Scheinkman, M., \& Malpas, J. (2013). Breaking the Mold: Sculpting Impasses in Couples' Therapy. Family Process, 52(1), 33-45. https://doi.org/10.1111/ famp. 12022

Reiter, M. D. (2016). Solution-focused sculpting. Journal of Systemic Therapies, 35(3), 30- 41. https://doi.org/10.1080/08975353.2018.1545102

Robert, M. \& Simon, D., (1998). Sculping The family. Family Process, 11(1), 49-57. https://doi.org/10.1111/j.1545-5300.1972.00049.x

Satir, V. (1972). Peoplemaking. Palo Alto, CA: Science \& Behavior Books.

Whitaker, C. \& Bumberry, W. (1988). Dancing with the Family: A Symbolic-Experiential Approach. London: Routledge.

\section{JOANA SEQUEIRA}

Professora auxiliar no Instituto Superior Miguel Torga, Coimbra Portugal. PhD em Psicologia Clínica, psicóloga clínica, terapeuta familiar. Docente supervisora da Sociedade Portuguesa de Terapia Familiar.

https://orcid.org/0000-0002-5635-2385

E-mail: joanasequeira@ismt.pt 